\title{
RETRACTABLE STABILIZER WHEEL SUPPORTED BICYCLE
}

\section{PRANAV MOHAN*, SACHIN SALIAN, DR SUDARSHAN RAO K \& SHARAN}

Department of Mechanical Engineering, Shri Madhwa Vadiraja Institute of Technology and Management, Karnataka, India

ABSTRACT
The present work relates to the design and fabrication of stabilizer wheel supported bicycle. Rider operable and
retractable stabilizer wheels were designed to be used as a rider's assistance to support weight of the rider during
impending, slowing and stopping the bicycle. The rider engages support wheels to obtain assistance while seated. To
engage and constrain the mechanisms manually, the present study involved the usage of hand-lever mechanism. In
addition, Shock absorbers were also provided to the stabilizer wheels to further improve the stability. The retractable
wheels were mounted with a provision of raising and lowering the wheels as per requirement with the help of twisted
metallic cables. Thus the installation of retractable stabilizer wheels would provide a hindrance free ride for bicycle
riders. This would further augment usage of bicycle in the general population and also in individuals who have difficulty
balancing on the road.
KEYWORDS: Hand Lever Mechanism, Retractable Stabilizer Wheels, Bicycle

Received: Jun 09, 2020; Accepted: Jun 29, 2020; Published: Aug 03, 2020; Paper Id.: IJMPERDJUN2020587

\section{INTRODUCTION}

A bicycle is a pedal driven vehicle having two wheels which are attached to a frame one behind the other. It is one of the most efficient modes of transportation in terms of energy applied and the output. Cycling is and has been used extensively in India. It provides various benefits in the form of no dependence on any energy sources, zero pollution and improved fitness. India has an increase in population, urbanization and economic growth over the years. Due to this there is increased traffic jam, difficulty in driving and increased pollution. In the present generation most of the youth and adults are obese and the main reason for this is they don't find time for exercising due to their heavy workload and stress.

Currently the technology of using a stabilizer wheel is restricted to kids and the designs are fixed structures which are removed once the kid learns to ride the bicycle. The literature review reveals that several patents have been claimed and got in stabilizing a bicycle.

David Willman (1991) have patented a retractable stop support wheels for a motorcycle by using hydraulic cylinders for actuation which gives stability during start and stop operation. Salvio Plana (2000) have patented a side wheel attachment for a bicycle by providing a coil spring structure replacing a single structural rod this can increase stability but only to a certain extent.

There are also studies which show usage of vertical spring loaded strut assemblies (Eisenmann, \&Yatron, 2001) to improve stability and vertical positioning of the bicycle. At present there is increased research on stability of autonomous vehicles (Cerone, Andreo, Larrson, \&Regruto, 2010) as well as stability analysis on stationary bicycles (Soudbakhsh, Zhang, \& Yi, 2012) but there is a lacunae in the domain of usage of stabilizer wheel supported bicycles for adults in India. Therefore, the aim for the study was to provide retractable stabilizer wheels 
supported bicycle to improve the stability of a conventional bicycle, also increase its usage in India among both children and adult.

\section{METHODOLOGY}

This work consisted of retractable stabilizer wheel which is manually operated using a hand lever mechanism. In the first phase, the design of the chassis was done using CATIA V5R20 and the material selected was mild steel, due to easy availability and less inexpensive compared to other materials.

[Insert figure 1]

Further static analysis of the chassis was done using ANSYS 14.5 to determine the total deformation, Elastic strain and Von Mises stresses.

Second Phase included the prototyping of the shock absorber. The shock absorber has four main parts namely, outer cylindrical shell, suspension spring, stopper plate with connecting rod and a threaded cover.

Phase 3 involved fabrication of U-shaped mild steel brackets for the wheels. This was done by cutting and welding to get the required shape. Two sets of mild steel top plates and bottom plates were fabricated. A fulcrum was placed to join the top and bottom plates together to form a foldable joint. Shock absorbers were then attached between the top and bottom plates of each wheel setup. This completed the wheel setup, then the brackets were welded to the bottom plates. The wheel setup was mounted on another fulcrum prepared on the swing arm of the bicycle. This allowed for motion during actuation and retraction.

[Insert Figure 2]

Phase 4 included the construction of Lever setup for actuation and retraction using a metal plate and a metal lever. Metal plate acted as a guide path for the lever. Lever was attached to the fulcrum enabling to and fro movement. Using twisted metal cables, lever was connected with the stabilizer wheels on either side.

Finally, cable tension and the cable lever play was calibrated according to the wheel actuation and retraction and its performance was tested by riding the fabricated bicycle.

[Insert Figure 3]

\section{RESULTS AND DISCUSSIONS}

The present study aimed at investigating the role of retractable stabilizer wheels in improving the stability of bicycle ride. The study also aimed to identify if the provision of shock absorber would further enhance the stability of bicycle ride.

It was found that by providing stabilizer wheels for a bicycle, the stability increased considerably and with the addition of the shock absorber the stability of the bicycle was further enhanced.

The second major finding was that design for the bicycle was cost effective when compared to other studies which used complex systems like gyroscope and electrical drives, thus making it affordable for the public.

It was also found that due to reduced complexity in the design, the system was less bulky compared to the other studies in review of literature.

[Insert Table 1] 
[Insert Figure 4]

[Insert Figure 5]

[Insert Figure 6]

From figure 4, the region shown in red depicts maximum total deformation taking place, which was at the region where the saddle was placed. The region shown in blue depicts the region where there was minimum deformation taking place since these regions are fixed supports the deformation was zero. Similarly in figure 5 and figure 6 the region from blue to red depicts the range of equivalent strain and stress from minimum to maximum value.

As depicted in figure 4, 5 and 6 the analysis of the chassis shows that as per the design, the range of total deformation was $0 \mathrm{~m}$ to a maximum of $2.1867 \mathrm{e}-008 \mathrm{~m}$, the range of equivalent elastic strain is $6.5645 \mathrm{e}-013 \mathrm{~m} / \mathrm{m}$ to $5.7508 \mathrm{e}-$ $010 \mathrm{~m} / \mathrm{m}$ and the range of equivalent Von Mises stresses is $4.8307 \mathrm{e}-002 \mathrm{~Pa}$ to $113.73 \mathrm{~Pa}$ when a load of $800 \mathrm{~N}$ was applied.

\section{CONCLUSIONS}

Retractable stabilizer wheel supported bicycle helps to attain proper balance during riding and helps the rider to run the bicycle comfortably thereby reducing the risk of falling or any other accidents caused due to imbalance. It motivates people to prefer bicycles thereby making people prefer bicycle for travelling short and long distances.

This bicycle can be accessed by both children and adult and also benefits people who have a shorter height and for the population who have difficulty in judging due to some neurological problems. This study can be further developed in future by inculcating electrical actuation for the stabilizer wheels.

\section{ACKNOWLEDGEMENT}

We would like to express our heartfelt gratitude to Mr Shishir for supplying the necessary parts and material for our study.

\section{REFERENCES}

1. Cerone, V., Andreo, D., Larsson, M., \& Regruto, D. (2010). Stabilization of a riderless bicycle: A linear-parameter-varying approach. In IEEE Control Syst. Mag.

2. Cherian, Shaun Thomas, and S. Suresh Kumar. "Analysis and Solution for Resolving Hydraulic Hose Failures in Backhoe Loaders. "International Journal of Mechanical and Production Engineering Research and Development (IJMPERD) 9., Dec 2019, 1021-1034

3. Eisenmann, I. A. A., \&Yatron, P. J. (2001). U.S. Patent No. 6,331,012. Washington, DC: U.S. Patent and Trademark Office.

4. García et al (2018). Stabilizing an urban semi-autonomous bicycle. IEEE Access, 6, 5236-5246.

5. Plana, S. (2000). U.S. Patent No. 6,113,122. Washington, DC: U.S. Patent and Trademark Office.

6. Samak, Chinmay Vilas, and Tanmay Vilas Samak. "Design of a Two-Wheel Self-Balancing Robot with the Implementation of a Novel State Feedback for PID Controller using On-Board State Estimation Algorithm." (2018): 1-10.International Journal of Robotics Research and Development (IJRRD) 8. 2, Dec 2018, 1-10

7. Soudbakhsh et al(2012, June). Stability analysis of human rider's balance control of stationary bicycles. In 2012 American Control Conference (ACC) (pp. 2755-2760). IEEE. 
8. Nguyen, Trong Trung, Duong. Van Tu, and Huy Hung Nguyen. "Remote Discrete-Time Model Reference Adaptive Control of a Two-Wheeled Mobile Robot."International Journal of Mechanical and Production Engineering Research and Development IJMPERD) 9. 4, Aug 2019, 1325-1334

9. Nikam, Harshal, Prem Mishra, and Sayali Bharambe. "Design and Analysis of Brake Rotor with Parameter Optimization." International Journal of Automobile Engineering Research and Development (IJAuERD) 4.4 (2014): 21-30.

10. Willman, D. M. (1991). U.S. Patent No. 5,029,894. Washington, DC: U.S. Patent and Trademark Office.

\section{APPENDIX}

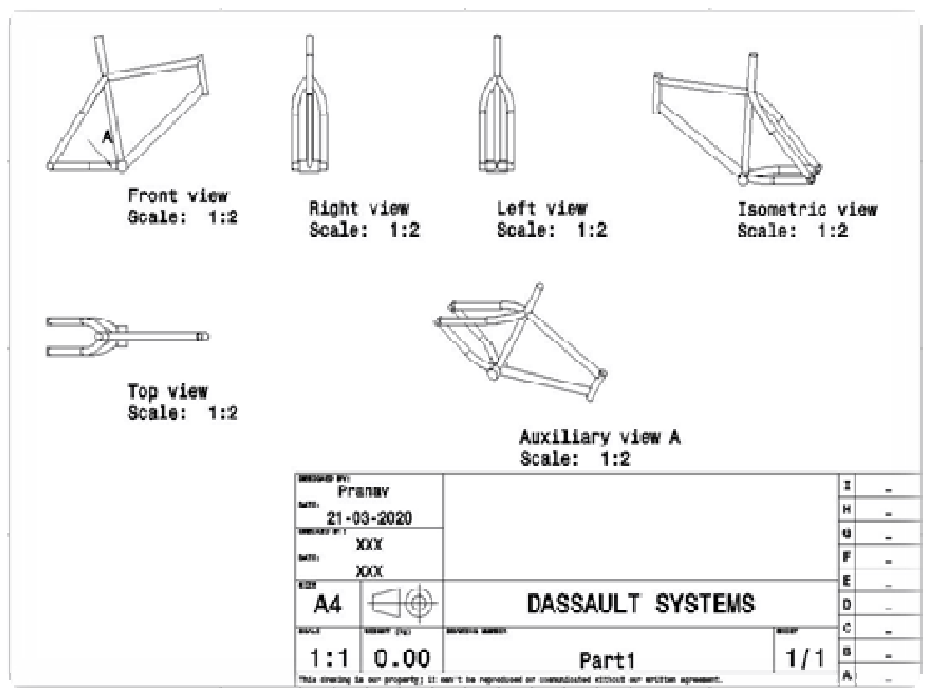

Figure 1: Different Views of Designed Chassis using CATIA Software.

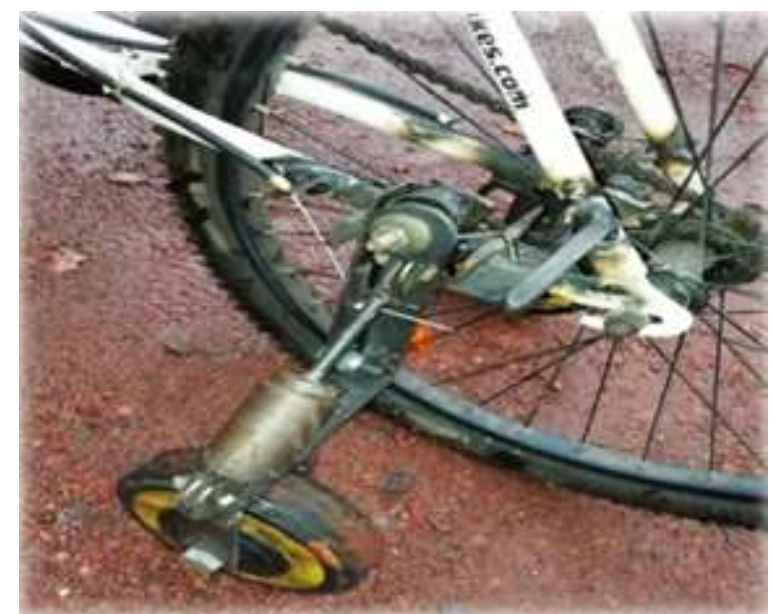

Figure 2: Fabricated Stabilizer Wheel Assembly with Shock Absorber and Brackets. 


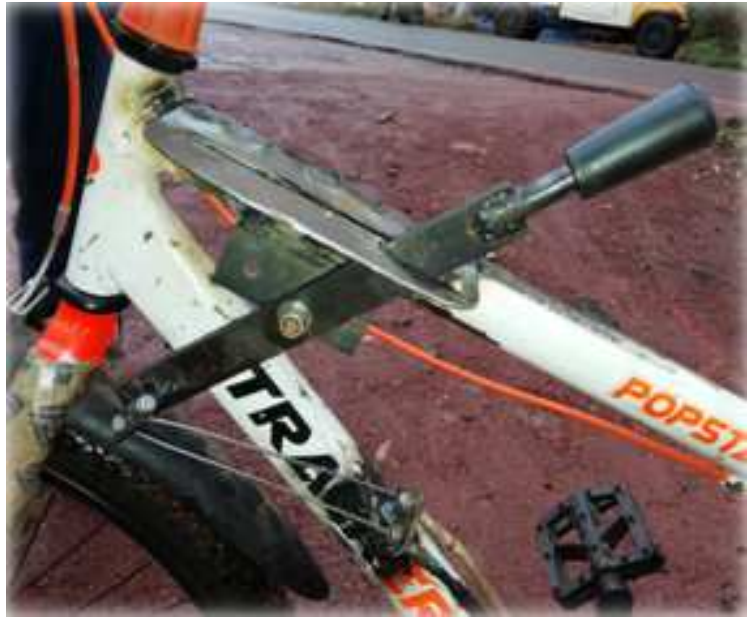

Figure 3: Lever Assembly.

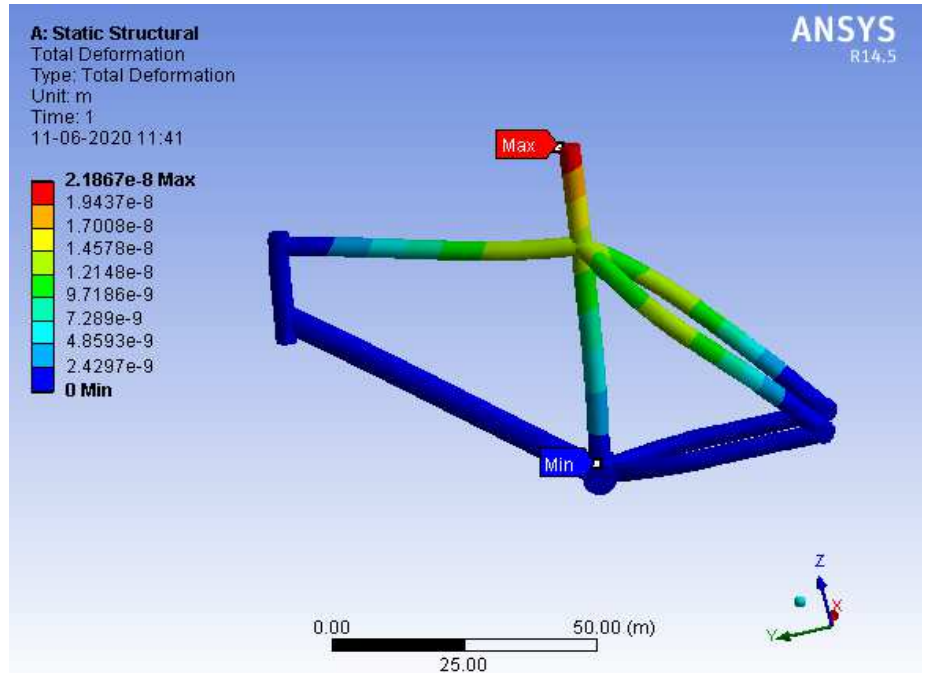

Figure 4: Total Deformation of Chassis of the Designed Bicycle.

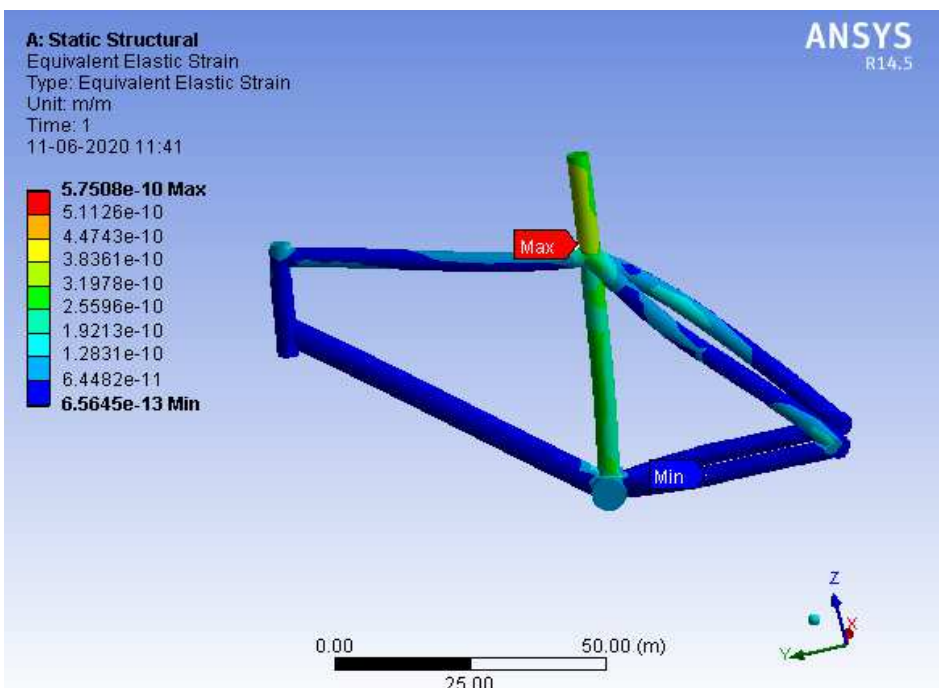

Figure 5: Equivalent Elastic Strain of Chassis of the Designed Bicycle. 


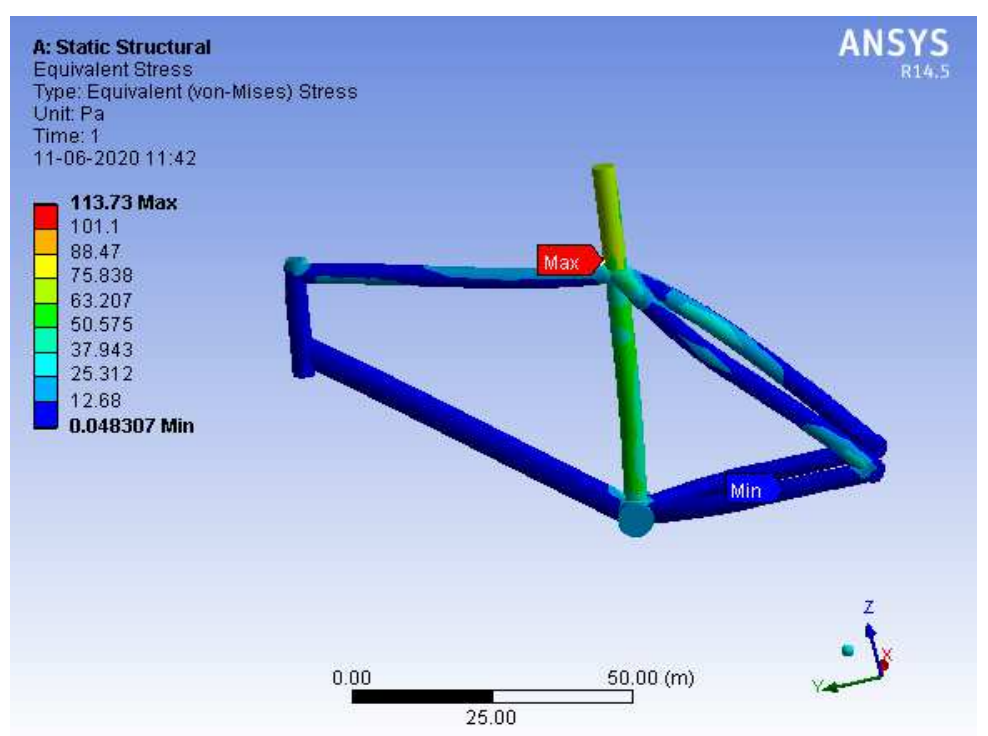

Figure 6: Equivalent Elastic Stress of Chassis of the Designed Bicycle.

Table 1: The Total Deformation, Equivalent Elastic Strain and Stress of Chassis of the Designed Bicycle when 800N Load is Applied

\begin{tabular}{|c|c|c|c|}
\hline \multicolumn{5}{|c|}{ DEFINITION } \\
\hline Type & Total Deformation & Equivalent Elastic Strain & $\begin{array}{c}\text { Equivalent (Von-Mises) } \\
\text { Stress }\end{array}$ \\
\hline \multicolumn{3}{|c|}{ RESULTS } \\
\hline Minimum & $0 \mathrm{~m}$ & $6.5645 \mathrm{e}^{-013} \mathrm{~m} / \mathrm{m}$ & $4.8307 \mathrm{e}^{-002} \mathrm{~Pa}$ \\
\hline Maximum & $\begin{array}{c}2.1867 \mathrm{e}^{-008} \\
\mathrm{M}\end{array}$ & $5.7508 \mathrm{e}^{-010} \mathrm{~m} / \mathrm{m}$ & $\begin{array}{c}113.73 \\
\mathrm{~Pa}\end{array}$ \\
\hline
\end{tabular}

